\title{
Restaurant outbreak of Legionnaires' disease associated with a decorative fountain: an environmental and case-control study Rosalyn E O'Loughlin*1,2, Lon Kightlinger ${ }^{3}$, Matthew C Werpy ${ }^{3}$, Ellen Brown ${ }^{1}$, Valerie Stevens ${ }^{1}$, Clark Hepper ${ }^{3}$, Tim Keane ${ }^{4}$, Robert F Benson ${ }^{1}$, Barry S Fields ${ }^{1}$ and Matthew R Moore ${ }^{1}$
}

Address: ${ }^{1}$ Respiratory Diseases Branch, Division of Bacterial Diseases, National Center for Immunization and Respiratory Diseases, Centers for Disease Control and Prevention, Mailstop C-23, 1600 Clifton Road NE, Atlanta GA 30333, USA, ${ }^{2}$ Epidemic Intelligence Service Program, Office of Workforce and Career Development, Centers for Disease Control and Prevention, 1600 Clifton Road NE, Atlanta GA 30333, USA, ${ }^{3}$ State of South Dakota Department of Health, 600 East Capitol Avenue, Pierre, SD 57501, USA and ${ }^{4}$ Legionella Risk Management, Inc, 31 Marian Circle, Chalfont, PA 18914, USA

Email: Rosalyn E O'Loughlin* - ROLoughlin@cdc.gov; Lon Kightlinger - Lon.Kightlinger@state.sd.us;

Matthew C Werpy - Matt.Werpy@state.sd.us; Ellen Brown - EBrown@cdc.gov; Valerie Stevens - VStevens@cdc.gov;

Clark Hepper - Clark.Hepper@state.sd.us; Tim Keane - tk@eicconsultants.com; Robert F Benson - RBenson@cdc.gov;

Barry S Fields - BFields@cdc.gov; Matthew R Moore - matt.moore@cdc.hhs.gov

* Corresponding author

Published: 9 August 2007

BMC Infectious Diseases 2007, 7:93 doi:10.1 186/1471-2334-7-93
Received: 12 September 2006

Accepted: 9 August 2007

This article is available from: http://www.biomedcentral.com/I47I-2334/7/93

(c) 2007 O'Loughlin et al; licensee BioMed Central Ltd.

This is an Open Access article distributed under the terms of the Creative Commons Attribution License (http://creativecommons.org/licenses/by/2.0), which permits unrestricted use, distribution, and reproduction in any medium, provided the original work is properly cited.

\begin{abstract}
Background: From June to November 2005, 18 cases of community-acquired Legionnaires' disease (LD) were reported in Rapid City South Dakota. We conducted epidemiologic and environmental investigations to identify the source of the outbreak.

Methods: We conducted a case-control study that included the first 13 cases and 52 controls randomly selected from emergency department records and matched on underlying illness. We collected information about activities of case-patients and controls during the 14 days before symptom onset. Environmental samples $(n=291)$ were cultured for Legionella. Clinical and environmental isolates were compared using monoclonal antibody subtyping and sequence based typing (SBT).

Results: Case-patients were significantly more likely than controls to have passed through several city areas that contained or were adjacent to areas with cooling towers positive for Legionella. Six

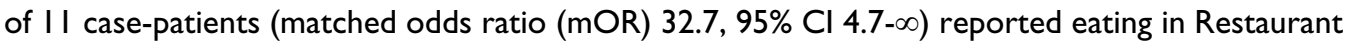
A versus 0 controls. Legionella pneumophila serogroup I was isolated from four clinical specimens: 3 were Benidorm type strains and I was a Denver type strain. Legionella were identified from several environmental sites including $24(56 \%)$ of 43 cooling towers tested, but only one site, a small decorative fountain in Restaurant A, contained Benidorm, the outbreak strain. Clinical and environmental Benidorm isolates had identical SBT patterns.
\end{abstract}

Conclusion: This is the first time that small fountain without obvious aerosol-generating capability has been implicated as the source of a LD outbreak. Removal of the fountain halted transmission. 


\section{Background}

On average, 1675 cases of legionellosis are reported to the Centers for Disease Control and Prevention (CDC) annually by state health departments, the majority of which are Legionnaires' disease (LD) (CDC, unpublished data). It is estimated that between 8,000 and 18,000 persons are hospitalized with LD in the United States each year, suggesting that under-diagnosis or under-reporting are common [1]. One species of Legionella, Legionella pneumophila, is responsible for $90 \%$ of reported cases of LD in the United States and the majority of these are caused by Legionella pneumophila serogroup 1 ( Lp1) $[2,3]$.

Eighty percent of cases of LD are sporadic [4] and the source of Legionella for these cases is rarely known. In contrast, outbreaks, while rare, provide an opportunity to identify common sources of Legionella. Community LD outbreaks have frequently been associated with cooling towers [5-13], and whirlpool spas [14-17], and less frequently with evaporative condensers [18], air-scrubbers [19], supermarket misters [20], potable water [21,22], and decorative fountains [23].

In a three week period in June and July 2005, seven cases of LD among residents of Rapid City were reported to the South Dakota Department of Health (SDDH). In the previous 10 years, only two confirmed cases of LD had been reported to the SDDH from Rapid City. (Personal communication, Dr. Kightlinger) No common exposures among case-patients were initially apparent. In July 2005 , SDDH and CDC began an epidemiological and environmental investigation to identify the source of the outbreak and to prevent additional cases.

\section{Methods \\ Epidemiologic investigation}

We defined a case as a resident of, or visitor to, Rapid City, South Dakota who was diagnosed by a physician, either clinically or radiographically, with community-acquired pneumonia (CAP) with onset after May 1, 2005 and who had laboratory confirmation of LD by culture of Legionella, by urinary antigen test for $L p 1$, by a four-fold or greater rise in serum antibody titer to $L p 1$, or detection of specific Legionella antigen by direct fluorescent antibody staining.

To enhance surveillance for additional cases of LD associated with Rapid City, alerts regarding the increase in cases were made locally (July 2005), statewide (July 2005), and nationwide (August 2005), to public health practitioners, physicians and health facilities. Clinicians were encouraged to perform urine testing for LD for all hospitalized patients with CAP and to report any cases to SDDH. To determine whether the increase in cases represented an outbreak or simply increased diagnostic testing, we exam- ined trends in admissions for CAP to Rapid City Regional Hospital, and Legionella urine antigen testing. Hypothesis generating interviews were held with the first six casepatients or their surrogates in an attempt to identify any common exposures.

We conducted a matched case-control study that included the first 13 of the 18 case-patients to identify exposures associated with $\mathrm{LD}$. The remaining five case-patients were not enrolled as they were reported after the source of the outbreak had been identified and publicized. Four controls per case $(n=52)$ were matched on underlying illness category (healthy, underlying illness or immunocompromised) and smoking status. As all enrolled case-patients were white, older than 50 years, and residents of Rapid City, we restricted our controls to white persons over the age of 50 years from Rapid City. Controls were selected randomly from among persons attending the local hospital's emergency department within seven days before or after the illness onset date of the corresponding casepatient. Potential controls who had a diagnosis of CAP in the last six months, who were residents of a long-term care facility, or who had been away from home for five or more nights during the two weeks of interest were excluded. We interviewed all case-patients or their surrogates in person and interviewed controls either in person, or by phone if they were unwilling to meet an investigator in person.

During interviews with case-patients and controls, we used a map of Rapid City and a calendar to prompt recall of activities during each two-week period of interest. Casepatients and controls were asked to refer to their diaries, check-books, and receipts to further assist with recall. Questions were general, such as "did you visit any restaurants?" or "did you visit any supermarkets?" If the answer was in the affirmative then the person was asked to specify which ones were visited. Reported routes of travel throughout the city were traced on a map which was divided into 180 grids, where each grid represented 1.29 $\mathrm{km}^{2}$, and the grid coordinates were recorded.

Matched analysis of the matched sets using exact methods in SAS version 9.1 (Cary, NC) was used to compute matched odds ratios (mOR) and 95\% confidence intervals (CI).

\section{Environmental investigation}

We conducted an environmental assessment of the city to locate aerosol-generating devices. The devices were identified by aerial, driving, and walking surveys of the city and through contacts with city managers, local property managers, water treatment companies, and industrial plumbing contractors. In September 2005, SDDH contracted an engineering consultant (TK) to assist in the environmental investigation and remediation efforts. Sample collec- 
tion and analysis were performed according to standard procedures [24]. Between July and November 2005, 291 environmental samples (201 water, 90 biofilm swabs) were collected from 123 potential sources at 73 sites throughout Rapid City. Sampling continued through the course of the outbreak initially concentrated in the documented areas of exposure of case-patients. Some sites were sampled more than once. Potential sources sampled included cooling towers, chiller units, supermarket misters, swamp coolers, decorative fountains, whirlpool spas, the municipal water system, wells and a stream. We also sampled the potable water system from the first seven case-patient homes, but as we found only one sample positive for Legionella, we discontinued this sampling as we concluded that acute dissemination of Legionella via the municipal water system was an unlikely explanation for this outbreak.

A one-liter water sample and, where appropriate, a biofilm swab were taken from each location. Water samples were collected in sterile plastic bottles containing a $0.1 \%$ sodium thiosulfate solution. Samples were shipped to the Legionella Laboratory at CDC (Atlanta, GA) or to the Special Pathogens Laboratory, Pittsburgh Veterans Administration Medical Center where Legionella was identified using previously described methods [3]. Clinical and environmental isolates were compared using monoclonal antibody (MAb) subtyping [25] and sequence based typing (SBT) [26].

Research was conducted in compliance with guidelines of the U.S. Department of Health and Human Services as they apply to epidemic investigations by the U.S. Public Health Service, CDC.

\section{Results \\ Epidemiologic results}

Between June 27 and July 18, 2005, SDDH was notified of seven cases of LD among residents of Rapid City. Enhanced surveillance detected an additional 11 casepatients for a total of 18 cases being reported by November 2005. Sixteen case-patients were residents of Rapid City and two were South Dakota residents who had visited Rapid City. Fourteen (77.8\%) of 18 patients were hospitalized, and $1(5.6 \%)$ died. Onset dates ranged over a fivemonth period from May 26, 2005 to October 29, 2005 (Figure 1). Ten patients (56\%) were men. Ages ranged from 51 to 88 years (median, 67 years). Eleven $(61.1 \%)$ patients had at least one medical risk factor for LD; diabetes mellitus was the most common $(\mathrm{n}=7)$. One patient was a current smoker and seven were former smokers. The diagnosis of $\mathrm{LD}$ was made for all patients by detection of Lp1 antigens in urine by enzyme immunoassay (EIA). Four case-patients were also diagnosed by isolation of $L p 1$ from respiratory secretions; 3 were Benidorm strain (MAb pattern 1, 2, 5, 7), a common outbreak strain, and one was Denver strain (MAb pattern 1,3,6), a relatively rare strain not previously associated with outbreaks (Figure 1). Data from Rapid City Regional Hospital showed an increase in Legionella urine antigen tests from November 2004 with no unusual increase in CAP or LD.

Thirteen of the 18 case-patients and 52 matched controls were enrolled in the case-control study. The median age of case-patients was 67 years (range 51-86) compared to 61 years (range 50-92) for controls. All case-patients and controls were residents of Rapid City and none were current smokers. Seven $(53.9 \%)$ of the 13 case-patients enrolled in the case-control study had a chronic underlying condition or were immunosuppressed.

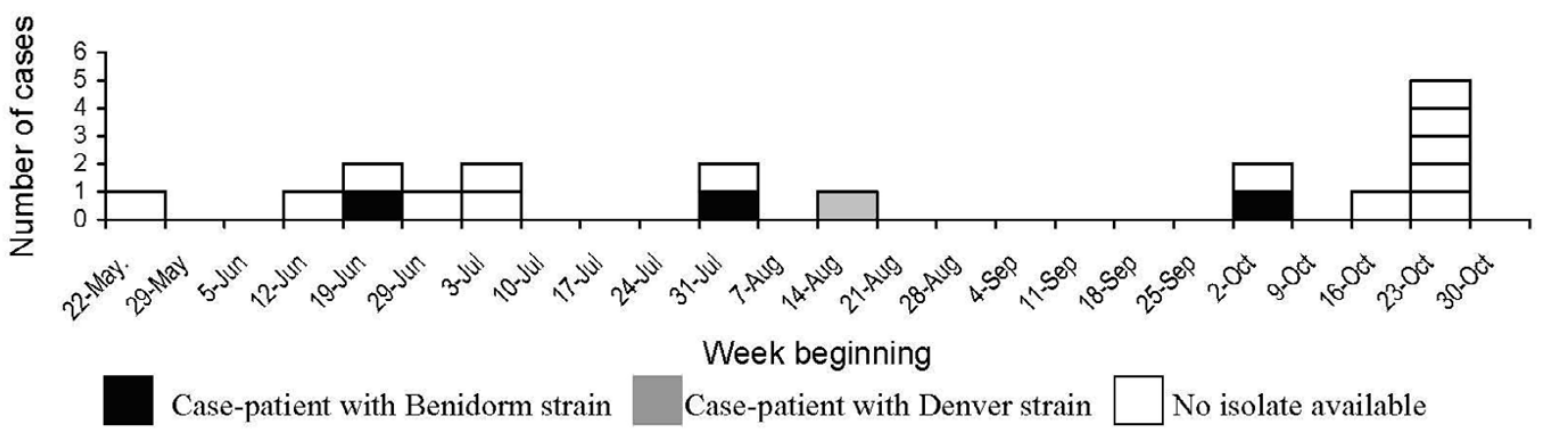

Figure I

Epidemiological curve of case onsets of LD in Rapid City, 2005. 
Case-patients were significantly more likely than controls to have passed through seven map grids (Table 1). Some of these grids were in, or adjacent to, grids with cooling towers colonized with Legionella (Figure 2). This initially supported the hypothesis that a cooling tower was the source of the outbreak. This was strengthened by the fact that no two patients lived or worked in the same building and among the first six case-patients, we could not place more than two case-patients in any one building or adjacent city blocks. Case-patients were not more likely than controls to have spent time outdoors (Table 1).

Table 1 presents matched odds ratios (mOR) for selected exposures. Apart from passing through certain map grids, visiting a restaurant was the only other activity with a statistically significant odds ratio. Six of 11 case-patients versus 0 controls (mOR 32.7) reported eating at Restaurant A during their first interview (information was unavailable for one case-patient and one case-patient was unsure). Six of seven case-patients were interviewed by the end of July and two reported eating at Restaurant A. Nine of 10 casepatients were interviewed by the end of July and three reported eating at Restaurant A. Finally, 12 of 13 casepatients were interviewed by the end of October and six reported eating at Restaurant A (the mOR is presented for the 6 of 11 cases who answered the restaurant question). After the public disclosure of Restaurant A as the source of the outbreak on October 29, 2005, all case-patients were re-contacted by SDDH to verify their exposure status and exposure date, and to ask how long they had spent in the waiting area where the fountain was located. Controls were not re-contacted. Simultaneously, some casepatients were prompted to contact SDDH to say they had eaten at Restaurant A despite not mentioning this in their initial interview. Ultimately, 10 (83\%) of 13 case-patients reported eating in Restaurant A within 14 days of their illness onset (two case-patient reported that they ate at Res- taurant A but were unsure of when, and one case-patient was not reported to have eaten in Restaurant A). Of the five case-patients not enrolled in the case-control study because they were reported after the fountain had been removed, all reported eating in Restaurant A. Restaurant A was located in map grid I8 which had a non-significant odds ratio (Figure 2).

\section{Environmental results}

Legionella was isolated from $43(35.0 \%)$ of 123 potential environmental sources and from 95 of 291 (32.6\%) samples (Table 2). Legionella pneumophila was the most common species identified and $L p 1$ was the predominant serogroup with 25 (58.1\%) of 43 sources positive for $L p 1$. Among the $L p 1$ isolates that were typed, strains reacting with MAb 1 were most common, suggesting the presence of type strain Camperdown (MAb 1) and/or Oxford 4032E (MAb 1,6). Due to a shortage of MAb 6 we were unable to distinguish between Camperdown and Oxford for all isolates although the few that were tested were Oxford.

The outbreak strain, Benidorm (MAb pattern 1, 2, 5, 7), was isolated from only one source, a decorative fountain in Restaurant A. Swabs were taken from the fountain basin, nozzle, and internal lamp and a water sample was taken. All were positive for Benidorm strain. We compared all Benidorm clinical and environmental isolates and found identical SBT patterns for the genes flaA, pilE, asd, mip, mompS, proA, i.e., the pattern $4,7,11,3,11,12$, respectively. The decorative fountain had a water Legionella colony count of $3000 \mathrm{cfu} / \mathrm{ml}$. Of the remaining water sources positive for Legionella that had colony counts recorded, 10 had counts less than $50 \mathrm{cfu} / \mathrm{ml}, 10$ had counts between 50 and $499 \mathrm{cfu} / \mathrm{ml}$, eight had counts between 500 and $1499 \mathrm{cfu} / \mathrm{ml}$, and three had counts above $1500 \mathrm{cfu} / \mathrm{ml}$.

Table I: Matched odds ratio for selected exposures

\begin{tabular}{|c|c|c|c|c|}
\hline Activity & Cases (\%) $N=13^{*}$ & Controls (\%) $\mathrm{N}=52 *$ & Matched OR & $95 \% \mathrm{Cl}$ \\
\hline Passed through grid E3 & $10 / 13(77)$ & $12 / 52(2 \mid)$ & 10.3 & $2.1-100.9$ \\
\hline Passed through grid E4 & $9 / 13(69)$ & $15 / 52(29)$ & 6.8 & $1.3-68.5$ \\
\hline Passed through grid F4 & $9 / 13(69)$ & $12 / 52(23)$ & 9.1 & $1.7-90.9$ \\
\hline Passed through grid F5 & $9 / 13(69)$ & $15 / 52(29)$ & 12.1 & I.5-558.5 \\
\hline Passed through grid F7 & $11 / 13(85)$ & $23 / 52(44)$ & 6.5 & I.3-65.4 \\
\hline Passed through grid F8 & $10 / 13(77)$ & $18 / 52(35)$ & 4.9 & I.2-29.3 \\
\hline Passed through grid $\mathrm{H} 6$ & $12 / 13(92)$ & $31 / 52(60)$ & 12.0 & I.3-597.4 \\
\hline$>1.5$ hours outdoors weekdays & $9 / 13(69)$ & $30 / 52(57)$ & 1.6 & $0.4-8.0$ \\
\hline$>1.5$ hours outdoors weekends & $6 / 13(46)$ & $30 / 52(57)$ & 0.65 & $0.2-2.5$ \\
\hline Visited any restaurant & $13 / 13(100 \%)$ & $29 / 52(56)$ & 17.7 & $2.5-8$ \\
\hline Reported eating in Restaurant A on first contact with SDDH & $6 / I I(55)$ & $0 / 44(0)$ & 32.7 & 4.7-8 \\
\hline Visited any food store & $7 / 13(54)$ & $38 / 52(73)$ & 0.5 & $0.1-1.9$ \\
\hline Visited any medical center & $7 / 13(54)$ & $43 / 52(83)$ & 0.2 & $0.03-1.1$ \\
\hline Traveled on main city thoroughfare & $10 / 12(83)$ & $33 / 48(69)$ & 2.2 & $0.4-22.0$ \\
\hline
\end{tabular}

*Denominators vary as not all case-patients answered all questions or were excluded because they were unsure. 


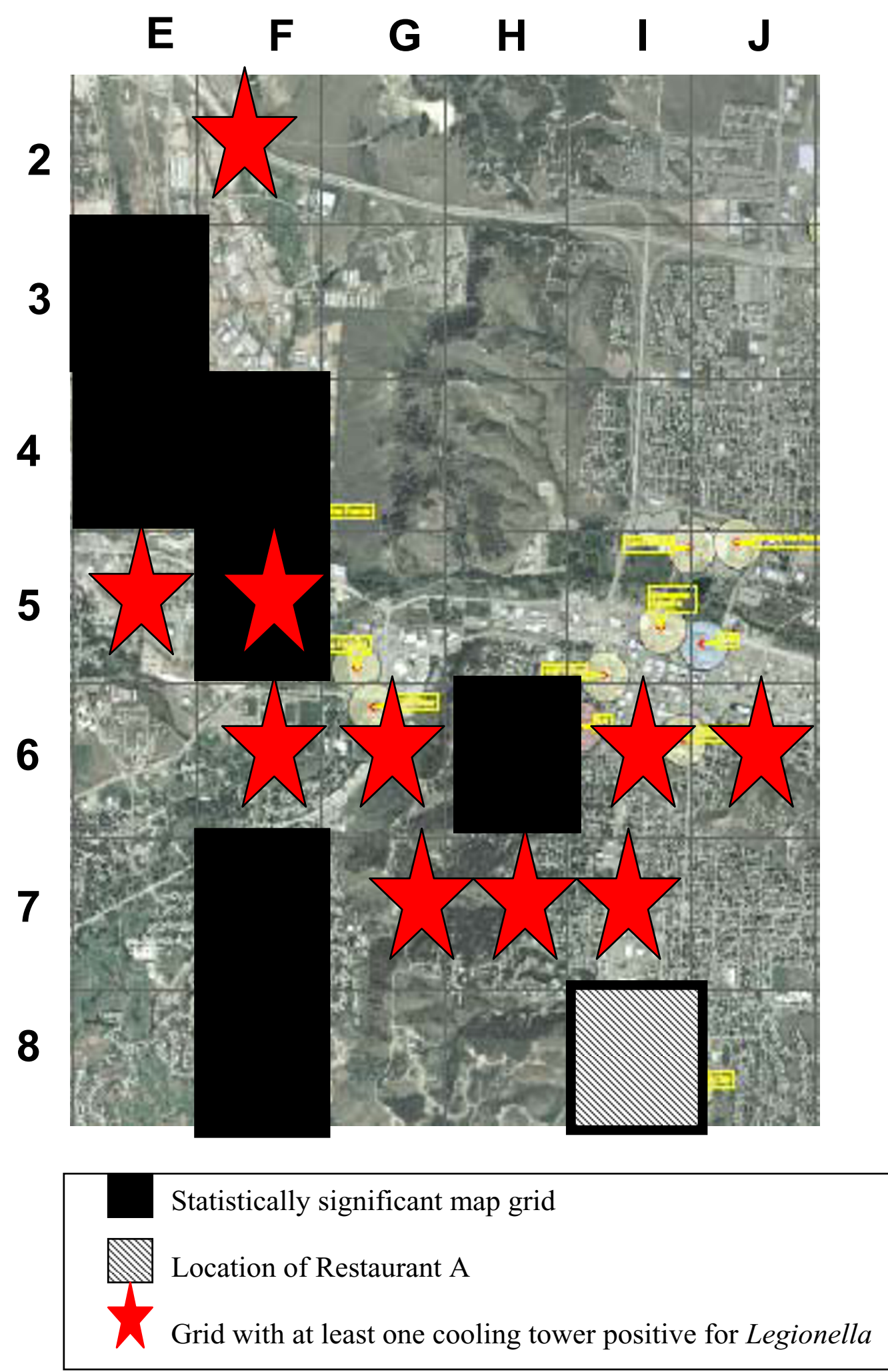

Figure 2

Segment of map of Rapid City. 
Table 2: Environmental sources positive for Legionella bacteria

\begin{tabular}{|c|c|c|c|c|}
\hline \multirow[b]{2}{*}{ Potential environmental sources } & \multicolumn{2}{|c|}{ Sources } & \multicolumn{2}{|c|}{ Samples } \\
\hline & Number investigated & Number (\%) positive & Number collected & Number $(\%)$ positive \\
\hline Case-patient homes & 7 & I (I4.3) & 37 & I (2.7) \\
\hline Cooling towers & 43 & $24(55.8)$ & 116 & $68(58.6)$ \\
\hline Chillers & 6 & $5(83.3)$ & 10 & $7(70)$ \\
\hline Swamp coolers and sumps & 9 & $5(55.6)$ & 12 & $5(41.7)$ \\
\hline $\begin{array}{l}\text { Decorative fountains and ornamental } \\
\text { waterfalls }\end{array}$ & 22 & $2(9.1)$ & 42 & $2(4.8)$ \\
\hline Municipal, local and industrial water sources & 22 & $3(13.6)$ & 39 & $6(15.4)$ \\
\hline Supermarket misters & 8 & $2(25.0)$ & 20 & $2(10)$ \\
\hline Whirlpool spa & I & $0(0.0)$ & 2 & $0(0.0)$ \\
\hline \multicolumn{5}{|l|}{ Restaurant A } \\
\hline Fountain & I & $\mathrm{I}(100)$ & 4 & $4(100)$ \\
\hline Other water sources & 4 & $0(0.0)$ & 9 & $0(0.0)$ \\
\hline Total & 123 & $43(34.7)$ & 291 & $95(32.6)$ \\
\hline
\end{tabular}

The decorative fountain located in the lobby of Restaurant A was sampled on October 24, 2005, turned off at that time of sampling, and removed a few days later. The diameter of the basin of the fountain was approximately $1.2 \mathrm{~m}$ with a central water column of approximately $30 \mathrm{~cm}$. The basin was covered with mesh and three colored lights were submerged in the water (Figure 3 ). The fountain operated for 10-12 hours per day. Restaurant A had seating capacity for 284 people. Case-patients reported a median of four minutes (range 0.5-17.5 minutes) spent in the lobby where the fountain was located. No employees of Restaurant A were reported ill. No cases of LD with an onset date of more than five days after the date the fountain ceased operation were reported in Rapid City. Denver strain, which was identified from one clinical isolate, was not identified from any environmental samples.

\section{Discussion}

We believe that the source of this outbreak was the decorative fountain in Restaurant $A$ for a number of reasons. The epidemiological evidence showed that even with poor case-patient recall the odds ratio from the case-control study showed a strong association between eating at restaurant A and having LD. The environmental investigation found Benidorm strain in the fountain in Restaurant A but not in any other potential environmental source. In addition, the strain isolated from the fountain and the three patient isolates were identical by SBT analysis. The colony count observed in the fountain, while very high, should be viewed as supportive but not decisive evidence of the fountain being the source.

This outbreak was unusual in that it lasted several months, a source that on observation appeared to generate only a small aerosol was implicated, and the casepatients had very short exposure periods. Previously a decorative fountain located in a hotel lobby was associated with an outbreak of LD [23] and a decorative fountain in a restaurant was linked with an outbreak of Pontiac Fever [27]. In addition, a decorative fountain located outdoors was the suspected source of an outbreak of LD in Portugal [28]. These fountains were significantly larger than the fountain implicated in this outbreak and were likely to have generated a larger aerosol. The fountain in Restaurant A was one of the many potential sources investigated early in the outbreak. Only sources that had a reasonable epidemiological link and that were considered to be a plausible source were sampled. Our initial assessment of the fountain in Restaurant A in July led us to conclude that it was an unlikely source because it appeared to generate very little aerosol, and because at that point only two casepatients reported having eaten at Restaurant A. Therefore, it was not sampled at that time but in October when we found a stronger epidemiological link. The fountain was reported to be out of operation for approximately 30 consecutive days during the time of this outbreak. Although the exact dates were unavailable to us, they appeared to correspond with the period on the epidemic curve when there were no cases. Rather than remediate the fountain in Restaurant A the fountain was permanently removed.

Our initial hypothesis was that a cooling tower was the source of this outbreak for three reasons. Firstly, we could find no common exposures and could not initially place more than two case-patients in any one building, leading us to believe that the source was outdoors. Previous studies have shown infections occurring as far as $6 \mathrm{~km}$ from an external source indicating that the wind is capable of transporting Legionella plumes [5]. However, exposure to contaminated cooling tower drift can occur indoors but in this situation there was no geographical clustering of patient homes which might have been expected if infection was as a result of a drift. Secondly, we found several cooling towers with Legionella in the city close to areas 


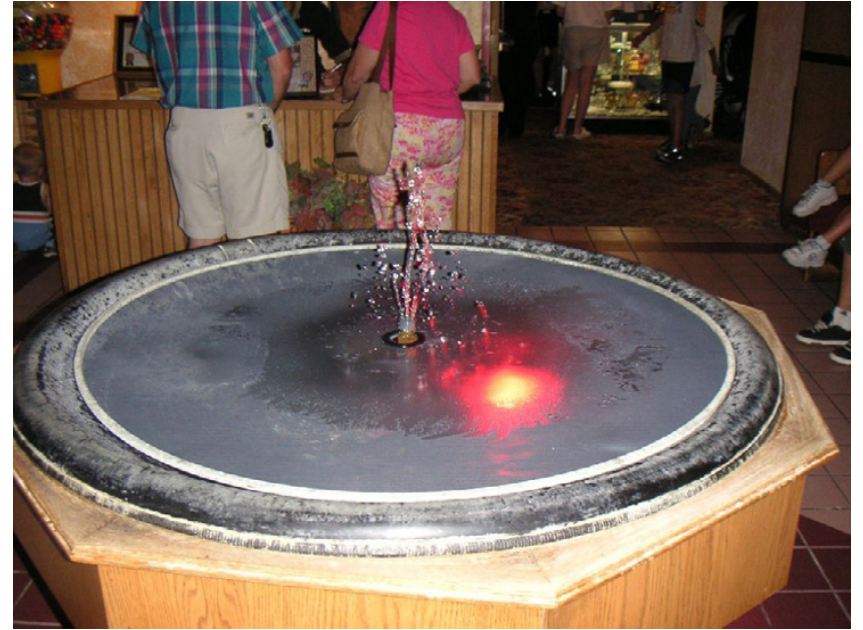

Figure 3

Decorative fountain situated in the lobby of Restaurant $A$.

where people shopped and worked, and to map grids through which case-patients were significantly more likely than controls to have traveled. Apart from exposure to cooling towers (using map grids as a proxy), analysis of potential exposures where more than half the casepatients had visited did not initially show any significant differences between case-patients and controls. This hypothesis was strengthened by the timing of the outbreak at the start of summer with many towers bearing heavier cooling loads and running in excess of $100 \%$ capacity due to a hotter than usual summer in South Dakota. Thirdly, as outlined in the background, cooling towers are common sources of community outbreaks of LD.

Clinicians at the local hospital in Rapid City had adopted a policy in November 2004 of more intensive diagnostic testing for patients with CAP so that antibiotic therapy could be targeted. Legionella urine antigen testing therefore increased prior to detection of this outbreak. This highlights the importance of appropriate diagnostic testing in patients with CAP. While many patients with LD can be treated successfully and empirically with antibiotics currently recommended for CAP, this outbreak shows that the use of etiology-specific diagnostic tests can lead to a public health intervention that prevents future cases of LD. Furthermore, increasing physician awareness and use of the urinary antigen testing, through our recommendation during the outbreak to test all new cases of CAP for $\mathrm{LD}$, may have improved patient management and contributed to the relatively low case-fatality rate. The availability of clinical isolates of Legionella from 4 case-patients was critical in allowing us to identify the source of the outbreak. In the United States there has been a steady decline in the proportion of LD cases diagnosed by culture since the introduction of urine antigen testing [2]. However, as this outbreak demonstrates, diagnostic testing of persons with CAP should include collection of urine for antigen testing and respiratory specimens for culture of Legionella whenever possible. This recommendation is included in the recently updated Infectious Disease Society of America/American Thoracic Society (IDSA/ATS) guidelines on the management of CAP in adults [29].

Legionella was cultured from over half (55\%) of the cooling towers tested, several of which were positive for $L p 1$. Although the outbreak was assumed to be caused by Benidorm strain, which was not found in any of the cooling towers, the presence of Legionella in so many sources, some with high colony counts, and with the potential to aerosolize is worrying. Other studies have shown that detectable levels of Legionella are present in many cooling towers and other building water systems $[30,31]$. Some researchers advocate measurement of colony counts as a predictor of disease risk [30]. However, because measurement of colony counts is not standardized, no other source was initially evident, and because there is no known safe level of Legionella, we applied the precautionary principle and recommended that all positive towers be remediated regardless of their colony count. SDDH employed a Legionella consultant (TK) to manage remediation of the cooling towers in accordance with published guidelines [32], and to hold cooling tower maintenance workshops for industry and businesses in Rapid City and two other South Dakota cities.

Our investigation had certain limitations. While it is understandable that individuals recovering from serious illnesses would have some difficulties with recall of activities 1 to 2 weeks earlier, poor recall delayed our ability to identify Restaurant A as a potential source of the outbreak. We could have asked our case-patients and controls whether they visited each individual shop, restaurant, etc. in Rapid City. However, this would have made our already lengthy questionnaire unwieldy. Case-patients were reinterviewed about their exposure to Restaurant A but controls were not re-interviewed. Therefore, we have not presented new matched odds ratios as they may be biased. Given the magnitude of the odds ratio (mOR 32.7) based on the initial case-patients' reported attendance at Restaurant $\mathrm{A}$ and given that the Benidorm strain was found only in the fountain in Restaurant $\mathrm{A}$, we believe that not reinterviewing controls has not weakened our conclusions that the fountain in Restaurant A was the source of this outbreak. We excluded the last five cases from the casecontrol study because they were reported after the source of the outbreak was published and we were concerned that their responses may have been biased. We believe that these cases appeared rather suddenly because media attention may have led to increased medical care-seeking, 
increased diagnostic testing, increased reporting, or all three.

We were unable to explain the presence of Denver strain in the clinical isolate of one case-patient. Although this patient ate at Restaurant $\mathrm{A}$, it is possible that this casepatient was infected by a different source and was a sporadic case unrelated to the outbreak. This assumes that the case-patients that were not culture confirmed were infected with Benidorm strain. It is also possible that Denver strain was present in the fountain but was masked by the predominance of Benidorm strain, or that Denver was present in the fountain in early August when this casepatient became ill, but was no longer present in late October when the fountain was sampled. These hypotheses also make it possible that Benidorm strain may have been present in cooling towers but was not present at the time of sampling. If that were the case however, one might have expected more people who had not eaten at Restaurant A to be case-patients. We interviewed approximately half of the controls by phone whereas all case-patients were interviewed in person. This may have led to better recall among cases. Interviews with controls by phone facilitated more rapid recruitment of controls and thus a more timely analysis.

Most of the fountains we sampled had little or no routine maintenance although this is recommended by fountain manufacturers and by the American Society of Heating, Refrigeration, and Air-conditioning Engineers (ASHRAE). ASHRAE guidelines are non-specific for fountain maintenance and are not disseminated widely in the restaurant industry [32]. Proper care and maintenance of ornamental water fixtures, such as decorative fountains, is essential to prevent outbreaks of LD and can be achieved by increasing awareness among fountain operators of the importance of adequate maintenance.

\section{Conclusion}

Small decorative fountains pose a previously unrecognized source of Legionnaires' disease outbreaks as we believe this is the first time that such a small fountain with apparently limited aerosol-generating capability has been implicated as the source of an LD outbreak. Investigations of future community outbreaks of LD should consider exposures to indoor decorative fountains, including small ones such as those that might be present in restaurants, hotels, or other businesses, as potential sources of Legionella.

\section{Competing interests}

TK was contracted by SDDH to assist with this outbreak investigation as an environmental engineering consultant specializing in Legionella remediation. His consultancy has no conflict of interest with any information contained in this paper.

The author(s) declare that they have no competing interests.

\section{Authors' contributions}

ROL, LK, MCW, CH, TK, BF and MRM participated in the conception and design of the study. ROL, LK, MCW, EB, VS, TK, RB, BF and MRM participated in the analysis and interpretation of data. ROL, MM and LK drafted the article. All authors critically revised the article for important intellectual content and all authors have seen and approved the final version. The corresponding author (ROL) had access to all data and had final responsibility for the decision to submit for publication.

\section{Disclaimer}

The findings and conclusions in this report are those of the authors and do not necessarily represent the view of the Centers for Disease Control and Prevention.

\section{Acknowledgements}

We would like to acknowledge the assistance of staff from the South Dakota Department of Health, Rapid City Regional Hospital, and the Respiratory Diseases Branch at CDC. We would like to acknowledge Janet $E$. Stout at the Pittsburgh Veterans Administration Medical Center, Special Pathogens Laboratory and Mike Smith at the South Dakota Public Health Laboratory for laboratory assistance, Brian Plikaytis and Kathryn Benton for statistical support, and Nick Hill, Kristin Wilson, Josh Clayton and Cherie Koch for assistance with field work. The study was funded by the Centers for Disease Control and Prevention and South Dakota Department of Health. All authors work for or were contracted by one of these organizations.

\section{References}

I. Marston BJ, Plouffe JF, File TM Jr., Hackman BA, Salstrom SJ, Lipman HB, Kolczak MS, Breiman RF: Incidence of community-acquired pneumonia requiring hospitalization. Results of a population-based active surveillance Study in Ohio. The Community-Based Pneumonia Incidence Study Group. Arch Intern Med 1997, I57(15): 1709-1718.

2. Benin AL, Benson RF, Besser RE: Trends in Legionnaires' disease, 1980-1998: declining mortality and new patterns of diagnosis. Clin Infect Dis 2002, 35(9): 1039-1046.

3. Fields BS, Benson RF, Besser RE: Legionella and Legionnaires' disease: 25 years of investigation. Clinical microbiology reviews 2002, I 5(3):506-526.

4. Marston B], Lipman HB, Breiman RF: Surveillance for Legionnaires' disease. Risk factors for morbidity and mortality. Arch Intern Med 1994, I54(21):2417-2422.

5. Nhu Nguyen TM, llef D, Jarraud S, Rouil L, Campese C, Che D, Haeghebaert S, Ganiayre F, Marcel F, Etienne J, Desenclos JC: A Community-Wide Outbreak of Legionnaires Disease Linked to Industrial Cooling Towers--How Far Can Contaminated Aerosols Spread? J Infect Dis 2006, 193(1): 102-III.

6. Rota MC, Pontrelli G, Scaturro M, Bella A, Bellomo AR, Trinito MO, Salmaso S, Ricci ML: Legionnaires' disease outbreak in Rome, Italy. Epidemiol Infect 2005, I33(5):853-859.

7. Garcia-Fulgueiras A, Navarro C, Fenoll D, Garcia J, Gonzales-Diego P, Jimenez-Bunuelas T, Rodriguez M, Lopez R, Pacheco F, Ruiz J, Segovia M, Balandron B, Pelaz C: Legionnaires' disease outbreak in Murcia, Spain. Emerg Infect Dis 2003, 9(8):915-921. 
8. Jansa JM, Cayla JA, Ferrer D, Gracia J, Pelaz C, Salvador M, Benavides A, Pellicer T, Rodriguez P, Garces JM, Segura A, Guix J, Plasencia A: An outbreak of Legionnaires' disease in an inner city district: importance of the first $\mathbf{2 4}$ hours in the investigation. Int J Tuberc Lung Dis 2002, 6(9):83 I-838.

9. Formica N, Tallis G, Zwolak B, Camie J, Beers M, Hogg G, Ryan N Yates M: Legionnaires' disease outbreak: Victoria's largest identified outbreak. Commun Dis Intell 2000, 24(7):199-202.

10. Kool JL, Buchholz U, Peterson C, Brown EW, Benson RF, Pruckler JM, Fields BS, Sturgeon J, Lehnkering E, Cordova R, Mascola LM, Butler $J C$ : Strengths and limitations of molecular subtyping in a community outbreak of Legionnaires' disease. Epidemiol Infect 2000, I 25(3):599-608.

II. Brown CM, Nuorti PJ, Breiman RF, Hathcock AL, Fields BS, Lipman HB, Llewellyn GC, Hofmann J, Cetron M: A community outbreak of Legionnaires' disease linked to hospital cooling towers: an epidemiological method to calculate dose of exposure. Int J Epidemiol 1999, 28(2):353-359.

12. Whitney CG, Hofmann J, Pruckler JM, Benson RF, Fields BS, Bandyopadhyay U, Donnally EF, Giorgio-Almonte C, Mermel LA, Boland S, Matyas BT, Breiman RF: The role of arbitrarily primed PCR in identifying the source of an outbreak of Legionnaires' disease. J Clin Microbiol I997, 35(7): 1800- 804.

13. Keller DW, Hajjeh R, DeMaria A, Fields BS, Pruckler JM, Benson RS, Kludt PE, Lett SM, Mermel LA, Giorgio C, Breiman RF.: Community outbreak of Legionnaires' disease: an investigation confirming the potential for cooling towers to transmit Legionella species. Clin Infect Dis 1996, 22(2):257-26I.

14. De Schrijver K, Dirven K, Van Bouwel K, Mortelmans L, Van Rossom P, De Beukelaar T, Vael C, Fajo M, Ronveaux O, Peeters MF, Van der Zee A, Bergmans A, leven M, Goossens H: An outbreak of Legionnaire's disease among visitors to a fair in Belgium in 1999. Public Health 2003, I I7(2): I I7-I 24.

15. Den Boer JW, Yzerman EP, Schellekens J, Lettinga KD, Boshuizen HC Van Steenbergen JE, Bosman A, Van den Hof S, Van Vliet HA, Peeters MF, Van Ketel RJ, Speelman P, Kool JL, Conyn-Van Spaendonck MA: A large outbreak of Legionnaires' disease at a flower show, the Netherlands, 1999. Emerg Infect Dis 2002, 8(I):37-43.

16. Benkel DH, McClure EM, Woolard D, Rullan JV, Miller GB Jr., Jenkins SR, Hershey JH, Benson RF, Pruckler JM, Brown EW, Kolczak MS, Hackler RL, Rouse BS, Breiman RF: Outbreak of Legionnaires' disease associated with a display whirlpool spa. Int J Epidemiol 2000, 29(6): $1092-1098$.

17. Jernigan DB, Hofmann J, Cetron MS, Genese CA, Nuorti JP, Fields BS, Benson RF, Carter RJ, Edelstein PH, Guerrero IC, Paul SM, Lipman $H B$, Breiman R: Outbreak of Legionnaires' disease among cruise ship passengers exposed to a contaminated whirlpool spa. Lancet 1996, 347(9000):494-499.

18. Breiman RF, Cozen W, Fields BS, Mastro TD, Carr SJ, Spika JS, Mascola $L$ : Role of air sampling in investigation of an outbreak of legionnaires' disease associated with exposure to aerosols from an evaporative condenser. I Infect Dis 1990, I6 I(6): |257-|26I.

19. Nygård K: Update: Outbreak of legionnaires' disease in Norway traced to air scrubber. In Euro Surveill Volume 10. Issue 6 Eurosurveillance; 2005.E050609. I.

20. Mahoney FJ, Hoge CW, Farley TA, Barbaree JM, Breiman RF, Benson RF, McFarland LM: Communitywide outbreak of Legionnaires' disease associated with a grocery store mist machine. J Infect Dis 1992, 165(4):736-739.

21. MMWR: Legionnaires Disease Associated with Potable Water in a Hotel --- Ocean City, Maryland, October 2003-February 2004. Morbidity and Mortality Weekly Report 2005, 54(MM7): 165.

22. Joseph C, Morgan D, Birtles R, Pelaz C, Martin-Bourgon C, Black M, Garcia-Sanchez I, Griffin M, Bornstein N, Bartlett C: An international investigation of an outbreak of Legionnaires disease among UK and French tourists. Eur J Epidemiol 1996, I 2(3):215-219.

23. Hlady WG, Mullen RC, Mintz CS, Shelton BG, Hopkins RS, Daikos $\mathrm{GL}$ : Outbreak of Legionnaire's disease linked to a decorative fountain by molecular epidemiology. Am J Epidemiol 1993, 138(8):555-562.

24. U.S. Department of Health and Human Services: Procedures for the Recovery of Legionella from the Environment. Atlanta, GA , U.S. Department of Health and Human Services; 1994.
25. Maher WE, Para MF, Plouffe JF: Subtyping of Legionella pneumophila serogroup $I$ isolates by monoclonal antibody and plasmid techniques. J Clin Microbiol 1987, 25(I 2):228I-2284.

26. European Working Group for Legionella Infections : SequenceBased Typing (SBT) protocol for epidemiological typing of Legionella pneumophila, Version 2.0. [http://www.hpa.org.uk/ cfi/bioinformatics/ewgli/SBT protocol v2.pdf].

27. Jones TF, Benson RF, Brown EW, Rowland JR, Crosier SC, Schaffner $\mathrm{W}$ : Epidemiologic investigation of a restaurant-associated outbreak of Pontiac fever. Clin Infect Dis 2003, 37( I0): I292-1 297.

28. Correia AM, Goncalves G, Reis J, Cruz JM, Castro e Freitas JA: An outbreak of legionnaires' disease in a municipality in northern Portugal. Euro Surveill 200I, 6(7): $121-4$.

29. Mandell LA, Wunderink RG, Anzueto A, Bartlett JG, Campbell GD, Dean NC, Dowell SF, File TM Jr., Musher DM, Niederman MS, Torres A, Whitney CG: Infectious Diseases Society of America/American Thoracic Society consensus guidelines on the management of community-acquired pneumonia in adults. Clin Infect Dis 2007, 44 Suppl 2:S27-72.

30. Shelton BG, Flanders WD, Morris GK : Legionnaires' disease outbreaks and cooling towers with amplified legionella concentrations. Current Microbiology 1994, 28:359-363.

31. Brundrett GW: Surveys of Legionella in building services not associated with outbreaks. In Legionella and Building Services Oxford, Butterworth-Heinemann Ltd. ; 1992:167-189.

32. ASHRAE Standard Project Committee 12-2000: Minimizing the risk of legionellosis associated with building water systems. Atlanta, GA , American Society of Heating, Refrigerating and Air-Conditioning Engineers, Inc.; 2000:4.

\section{Pre-publication history}

The pre-publication history for this paper can be accessed here:

http://www.biomedcentral.com/1471-2334/7/93/prepub

Publish with Biomed Central and every scientist can read your work free of charge

"BioMed Central will be the most significant development for disseminating the results of biomedical research in our lifetime. "

Sir Paul Nurse, Cancer Research UK

Your research papers will be:

- available free of charge to the entire biomedical community

- peer reviewed and published immediately upon acceptance

- cited in PubMed and archived on PubMed Central

- yours - you keep the copyright

BioMedcentral 